\title{
Factors threatening mental health in organizations and offices
}

\author{
Mohamad Khaledian ${ }^{1, *}$, Galavizh Khaledian², Jabar Sadeghi ${ }^{2,3}$, \\ Reza Keyhanihekmat ${ }^{2,3}$ \\ ${ }^{1}$ Faculty of Psychology and Educational Sciences, Ghorveh Branch Islamic Azad University, \\ Ghorveh, Iran \\ 2Payame Noor University, PO BOX 19395 - 3697, Tehran, Islamic Republic of Iran \\ ${ }^{3} \mathrm{M} . \mathrm{A}$ in management and academic member of Ghorveh Branch Islamic Azad University, Iran \\ *E-mail address: mohamad_khaledian22@yahoo.com
}

\begin{abstract}
One of the important aspects of health is mental health. Job constitutes a major part of man's social life. Job plays a fundamental role through creating a situation for the participation of employees and working groups in meeting the social needs of humans like the need to respect. The objective of this research is to examine the Factors threatening mental health in organizations and offices. The method of research, documentation and library.
\end{abstract}

Keywords: mental health; Job constitutes; social life

\section{INTRODUCTION}

According to the world health organization definition, mental health means the ability to communicate coordinately with others, to improve social and personal environment, and to solve conflicts and personal inclinations rationally, justly and appropriately (Abbasi et al , 2002). The term mental health is an extended concept that includes mental well-being, the feeling of self-empowerment, competency, understanding inter generation relationship, and the ability to determine potential emotional, and intelligent talents in the sense the person can realize his abilities and adapt to the common life stresses and becomes helpful and efficient person from the view point of profession (Imam Hadi et al, 2007). Cheerfulness, joy and the feeling of being fortunate is one of divine blessings bestowed on man in the light of the mental health and well-being; In addition the mental health is one of the effective and important factors in the promotion and development of humans (Yousefi et al, 2011). However health is the necessary condition for fulfilling social roles. Thus people can perform their activities when they enjoy health (Seidahmadi, et al , 2011). A great part of man's life is assigned to work. Man secures his life needs through working and in the meantime enjoys working and lives because of that (Shafie abadi, 2006). Working is the necessity of development and development secures the benefits of the society and people. The working force forms the producing part and it is because of this that the circumstances, environment and attending to the mental health is of high importance (Dibaj, 2010). In recent years considerable advances in technology and 
industry have brought about a wave of stress that has led to a reduction in the health level of the society. Stress affects negatively human activities in different psychological, physical and familial areas. Production decrease, professional dissatisfaction, an increase in the number of accidents and errors as well as reduction in the publics' health levels are signs of stress. Although most professions are followed by mental pressure, practitioners understand how to deal with tension pressures. Despite all the stress creating stimuli they face daily, they know very well how to avoid catastrophic impacts of them. However some are not very well prepared to avoid these impacts or escape them, thereby are exposed to them (Saatchi, 1998). According to Whiteman today in every situation people face with some degrees of nervous pressures and stress in the working situations and this is an undeniable and tangible subject in the modern organizations. Given the fact that at least one third of our life time is spent in the working situation and most of our social relations take place there, it can be regarded as a major part of our life (Attar, 1997).

Stress exists in all professions and exerts pressures in various ways. Professional developments like organizational changes, changes in payments and compensations, professional promotion, increase and decrease of the working force as well as social upheavals are matters that pressure people causing them to feel turbulent, worry, stressful and anxious. An efficient human force is a major index of the supremacy of one organization over the other. Therefore, professional employees, who are faithful and adaptable to the values and objectives of the organization posses a strong motivation and are inclined and committed to maintaining the organizational membership. Thus they are of the main and necessary needs of each organization. For an organization to be successful, it needs employees who work beyond their scope of common activities. The existence of such forces in the organizations not only reduces absence, delay and movement but also results in a considerable increase in the performance of the organization, mental rejoice of the employees, and representing elevated goals of the organization as well as achieving personal objectives. Generally speaking lack of the feeling of commitment and low commitment level engenders negative consequences for the person and the organization. Leaving duty, lack of interest in staying in the organization, low working quality, lack of faithfulness to the organization and illegal activities there, fault finding and backbiting the others, reduced trust in customers and low earnings are of these consequences (Robins, trans. By Parsayan and Arabi, 1997).

Employees with high commitment are enthusiastic and work more for the sake of the organization. The persons' strong obligation towards the organizations allows for better adaptations and more accountability to changes regarding demands by the customers. It also creates a situation where people are more prepared to adapt to pressures and environmental stresses. In most organizations, employees are major agents that affect efficacy, efficiency, and professions performances in the organizations. Therefore for a successful performance, each organization is interested in employees who are committed to it and its objectives (Ghamari, 2010). Saravastawa (1991) in a research found the professional stress is correlated positively with mental diseases and psychic problems. The mental health of people is one of the important and effective characteristics in the organizational psychology and relations. So far different definitions have been presented about the mental health. Lack of illnesses, having an emotional balance, social compatibility, feeling secure and comfortable, personality integrity recognition of the self, and environment and some other definitions (Schultz, 2006, trans. by Seid Mohamadi, 2009). Researches by Leong et al, (1996), Saorabe et al, (2008), revealed there is a significant relationship between the mental health and the organizational commitment by teachers, nurses and employees. According to the fact that some of the stress generating factors in the profession of nursing are inevitable, taking measures to prevent mental and behavioral 
impacts of stress on the practitioners through adopting measures in the direction of improving the working situation and training methods to deal with it is among responsibilities that managers of organizations providing medical and health services have to assume.

The substantive prevalence of disorder in the mental health requires special attention and organizational interventions including encouraging group work, participating the personnel in the decision making processes, professional supports, decreasing conflicts and professional ambiguities and increasing control over professional eventualities (Khaghanizade, et al, 2007). One of the most important effective variables on performance is professional satisfaction. The professional satisfaction represent positive and negative feelings and approaches regarding our own professions and hence it is dependent on many factors related to the profession whose scope extends from the place where the person stands until he achieves a feeling in doing something (Mehdad, 2011). The professional satisfaction refers to a set of inclinations or positive feelings that people have with respect to their profession (Anderson, 2001). In other words, to the extent a person likes his profession, he can meet his needs through that and as a result feels positive. In other words, the professional satisfaction as a psychic pleasure derives from satisfying needs, inclinations and hopes that the person achieves in relation with what he does (Robins, 2008).

The professional satisfaction factors are satisfaction with the nature of the profession, satisfaction with compensation, satisfaction with the supervisor, satisfaction with colleagues and satisfaction with promotion. Satisfaction with the nature of the profession as one of the important factors in the personal professional satisfaction is measured in respect of positive and negative feelings regarding the degree of responsibility, working activities, training opportunities and diversity of the profession. Satisfaction with compensation is defined in respect of the rate of the salary received and equality and fairness in the payment. Satisfaction with supervisor is expressed in the extent to which the supervisor is interested to show care and attention towards his employees. Satisfaction with colleagues is one of the effective aspects of the overall satisfaction of the person that includes friends, colleagues and others that are supportive.

Promotion could involve a range including a positive change in the salary, compensation, being scrutinized to a lesser extent, more working challenges, more freedom and responsibility in decision making processes. Bejwerk et al, (2007), showed in a research, should people feel that professional promotions are equal with their effort levels that meet their needs in comparison with others' salary payments and efforts, they are regarded as just and becomes satisfied with their profession. Hence, in response to these conditions they increase their own performances. Given to the fact that satisfaction factors like satisfaction with compensation have the ability to predict the professional stress, based on the exchange model (reciprocal response) by Lazarus and Folk man (1984), one can infer people evaluates the needs they bring with them to the working situation. If the working situation does not respond to these needs and the selected goals of the person are not met and the person believes that the social environment needs are more than what the he can afford, he faces with psychic pressures, thereby dissatisfaction with the organization is created. On the other hand, understanding the degree of the professional promotions could also affect the professional satisfaction and stress. According to the Adam's equality theory should people feel professional promotions are equal with their efforts levels that meet their needs and are regarded as just in comparison with what the others receive in terms of salary and compensation, they become satisfied with their own profession. 


\section{THE APPLICATION OF THE PERSONAL DIFFERENCES}

In choosing employees: When we intend to choose an appropriate person to assume a professional post, it should be borne in mind there are personal differences among the volunteers to assume that post.

In leadership and management: When we are entrusted with managing and controlling a branch of an organization it is imperative that we keep in mind that some people work better when they are exposed to an authoritative leader ship style while some others do better and are more adaptable to a popular leadership (advisory) style. If a person is asked what activities he intends to perform, he does well at that while some others prefer to have creativity, innovation in fulfilling professional duties. The responsibility of a manager at a unit is to understand the people under his supervision and treat them in such a way that is motivated to fulfill their duties. In establishing professional motivations: In cases we intend to motivate people for increasing personal productivity in the direction of performing their professional duties better, it is imperative to pay attention to the existing personal differences. For example, if a person is told in case he is successful in doing his duty he'll receive more financial awards; it is highly likely that he will increase his performance. There is a possibility that the person increases his performance only for recognition in the organization and then financial incentives are unimportant to him. However, peoples' needs are different and each of them due to special reasons apply their maximum energy and power in performing their professional duties (Saatchi, 2012).

\section{OTHER IMPACTS OF THE ORGANIZATION ON PEOPLE}

Organizations have various effects on people through their special nature and these effects are neither necessarily destructive nor uncontrollable. One of the main dangers that threatens the person in the organization is that only a few of the managers are able to realize social effects (positive and negative), policies, and their decisions on the employees under their supervision. Presently, it is likely that conflicts and differences arise between organizational policies and peoples' natural development processes in the organization. On the other hand, since this issue is one sided mostly its consequences result in frustrations for the person in the organization.

The possibility of choice is narrow for the person in organizations, hence he can take the direction which is more appropriate and apply the rules and regulations in proportionate to the circumstances and conditions. It is expected from the employees of an organization to do whatever that is told to them and leave "thinking" and "contemplation" to their management whose competence is a matter of doubt in the sight of the employees. However, mostly in the industrial societies millions of adult people spend 40 hours of their time working in the organizations and they're forced not to apply their mental capacity. They are rather coerced to keep and maintain an organization that possesses no efficiency. In other words, millions of peoples' hours are lost and this itself renders in some other problems (Saatchi, 2012). Arjeris states that organizations cause their adult employees to face frustration through three main mechanisms and encourage other people having little emotional maturity to remain in the same situation. These three mechanisms are : the formal structure of the organization, leadership based orders, and controlling management ( Budget, incentive systems, and studies of the time to move). Arjeris maintains that a situation should be made where the managers are able to take step in satisfying peoples' needs in the organizations they work. He actually proposed an initial 
plan for applying this method. For him, no uniform system can at best adapt to different situations where organizations face in terms of distributing power inside.

For example, there is a difference between the management strategy designed for production and establishing an intimate relationship of employees and the managing and the other strategy used for reducing costs and increasing profits. Thus an appropriate organization is not the type of organization that possesses the ability to have a necessary adaption in case power is transferred to lower levels. But an appropriate organization is the one in which each section of it measures its own problems and selects that particular way of distributing power that looks more appropriate at a particular time. In other words, both the needs of the organization and those of the people should be satisfied.

The role of the manager could change based on the fact that to what extent the organization is administered through "traditional authoritarian" and "representative of the employees" (Saatchi, 2012). In the end it is recommended that in order to reduce the professional stress in industries and organizations, attention should be made to increasing matters including satisfaction with promotion, satisfaction with compensation, and satisfaction with colleagues. Because satisfaction affects the interpretation of the stress generating events, efforts should be made towards increasing the peoples' understanding regarding satisfaction criteria, thereby experiencing lower stress pressures. It is also recommended that the nature of work and factors affecting colleagues are investigated so as to enhance the performance of the employees.

\section{OTHER RECOMMENDATIONS}

Increasing psychological and consultancy services in organizations in order that employees learn to be more adaptable to professional stress pressures. Holding regular sessions for employees of the hospitals and encouraging them to solve problems and existing negative consequences in the working situation; Participating the employees in the decision making processes relating to changes in the working situation in the organization structure and the possibility of expressing opinions as well as investigating professional etiology and presenting applied guidelines on reducing stress generating factors; Increasing the awareness and adaptability level of the employees that are subject to stress; Increasing the awareness level of the management regarding appropriate planning and reducing stress arising from the working situation

\section{References}

[1] Asadzandi M., Syarim R., Ebadi A., Sanaeenasab H., Journal of military nedication 11(3) (2011) 135-141.

[2] Imamhadi M., Jalilvand M., Salehi M., Scientific and Research periodical of social welfare 5(20) (2007) 153-162.

[3] Khaghanizade M., Siratineir M., Abdi F., Kavyani H., Investigating the mental health of the nurses working in the training hospitals related to the Medical and Scientific University of Tehran. 8(31,32) (2007)141-148.

[4] Dibaj F., Pathology of profession in Qom, Salsabil Publication, 2010. 
[5] Robins Stephen, Basics of the organizational behavior. (trans: By Ali Parsayan and Mohamad Arabi, n 1997). Studies and trade research publications, 1997.

[6] Saatchim M., Productivity psychology. Tehran: Virayesh publication, 1997.

[7] Saatchim M., Psychology of profession, Tehran: Virayesh publication, 2012.

[8] Seidahmadi M., Keivanloo F., Kooshan M., Mohamadiraouf M., Journal of Medical Sciences and Health Services of the University of Sabzevar 17(2) (2010) 116-122.

[9] Safee abadi A., (2006). Guidance and professional advisory, Roshd publication, 2006.

[10] Schultz D., Sculktz S. A., Theories of personality. (Trans by Yahya Seidmohamadi, 2009). Tehran: Virayesh publication, 2006.

[11] Abbasali A., Panahanbari A., Kamkar A., Bagherizade A., Journal of Medicine 43 (2002) 34-38.

[12] Attar H., Investigating the reklationship between the professional stress and professional satisfaction in the mental health of the empoloyees of an industrial complex, M.A thesis iun psychology, Tehran, 1997.

[13] Anderson- Fele L., International Congress Series 1280 (2005) 341-346.

[14] Bjørk I. T., Samdal G. B., Hansen B. S., Tørstad S., Hamilton G. A., International Journal of Nursing Studies 44(5) (2007) 747-757.

[15] Leong C. S., Furnhama Copperc L.,The Moderating Effect of Organizational commitment on the Occupational stress outcome Relationship. Journal Human relations, 49 (1996)

[16] Srivastava A., Psychological Studies 36 (1991) 192-197.

[17] Saurabh Kr. Tiwari, P. C. Mishra, Journal of the India Academy of Applied psychology 34(2) (2008) 267-279. 